\title{
Effect of Lead on the Prenatal and Postnatal Development of Kidney in Albino Rat and the Possible Protective Effect of Vitamin C (Light and Electron Microscopic Study)
}

Ahmed El-Sayed Yousef, MSc ${ }^{1 *}$; Mohamed Mokhtar Al Assaly ${ }^{1}$, MD and Mohamed Al Hady Zahran, MD ${ }^{1}$

* Corresponding Author:

Mohammed Ahmed Yousef ay6319686@gmail.com

Received for publication July 5 , 2021; accepted August 11, 2021; published online September 10, 2021

Copyright 2021 The Authors published by Al-Azhar University, Faculty of Medicine, Cairo, Egypt. All rights reserved. This an openaccess article distributed under the legal terms, where it is permissible to download and share the work provided it is properly cited. The work cannot be changed in any way or used commercially.

doi: 10.21608/aimj.2021.83845.1517

${ }^{1}$ Department of Anatomy and Embryology, Faculty of Medicine Al-Azhar University.

\author{
ABSTRACT \\ Background: Lead poisoning between pregnant women is a significant \\ public health problem, as it affects development of fetuses.
}

Objective: To evaluate the histological changes in the kidney of rat pups at gestational day 18 and at postnatal day 21 and the impact of cotreatment with vitamin $\mathrm{C}$.

Material and Methods: This study was done at the Pharmacology Department Laboratory at Al-Azhar Faculty of Medicine, Cairo between April and June 2020. Twelve adult female rats and six adult male rats were used in this study. Twelve pregnant female rats were divided into two equal groups (prenatal and postnatal). Each group was divided into three subgroups. Group (IA, IIA): served as control group. Group (IB): given $10 \mathrm{mg} / \mathrm{Kg}$ of lead orally from the first day of pregnancy till $18^{\text {th }}$ day of gestation. Group (IC): given $10 \mathrm{mg} / \mathrm{Kg}$ of lead plus $40 \mathrm{mg} / \mathrm{Kg}$ of vitamin $\mathrm{C}$ orally from the first day of pregnancy till $18^{\text {th }}$ day of gestation. Group (IIB): given $10 \mathrm{mg} / \mathrm{Kg}$ of lead body orally from the first day of pregnancy till the post natal day 21. Group (IIC): given $10 \mathrm{mg} / \mathrm{Kg}$ of lead plus $40 \mathrm{mg} / \mathrm{Kg}$ of vitamin $\mathrm{C}$ orally from the first day of pregnancy till the post natal day 21 .

Results: In lead groups (prenatal and postnatal), there were histological changes and biochemical alterations in urea and creatinine. These results were improved in vitamin $\mathrm{C}$ co-treatment.

Conclusion: This study showed that vitamin $\mathrm{C}$ might have a protective effect against lead-induced nephrotoxicity.

Keywords: Prenatal; Postnatal; Lead; Vitamin C; Kidney; Rat.

Authorship: All authors have a substantial contribution to the article.

Disclosure: The authors have no financial interest to declare in relation to the content of this article. The Article Processing Charge was paid for by the authors.

\section{INTRODUCTION}

Lead is a toxic metal that induces a wide range of biochemical, behavioral and physiological effects in humans. Lead toxicity is probably the most common form of heavy metal intoxication. It is well documented as one of the most dangerous and insidious poisons. Its continuous occupational and environmental exposure may contribute to renal, hepatic, nervous, reproductive and hematological disorders in man and animals. ${ }^{1}$
The important sources of lead exposure include gasoline additives, ceramic glazes, lead-based paints, cosmetics, drinking water system, battery and plastic recycling industry. ${ }^{2}$

Lead is able to pass through the placenta and breast milk and blood lead levels in infants and mothers are usually similar. It had been associated with fetal wastage, premature rupture of membranes, and premature delivery ${ }^{3}$.

Vitamin C (vit. C) is an essential water-soluble 
antioxidant present in cells, plasma and body fluids. ${ }^{4,5}$ It is one of the most widely available antioxidant molecules due to mitigating oxidative damage. ${ }^{6}$

The aim of the present study was to evaluate the histological changes in the kidney of rat pups at gestational day 18 and at postnatal day 21 and the impact of co-treatment with vitamin $\mathrm{C}$.

\section{MATERIAL AND METHODS}

This study was carried out on eighteen albino rats (12 females and 6 male albino rats) weighing between 200-250 grams. This study was done at the Pharmacology Department Laboratory at Al-Azhar Faculty of Medicine, Cairo between April and June 2020. The rats were housed in stainless steel cages in controlled laboratory environment with a constant 12 hour light /12 hour dark cycle and at a temperature 20-32 $\mathrm{c}^{\circ}$, fed a standard balanced diet and water access. After acclimatization to laboratory conditions, every two female rats were kept overnight with one male rat to allow matting. The presence of spermatozoa in the vaginal smear in the next morning was an indicator as day zero of pregnancy. Subsequent days of gestation were numbered accordingly. ${ }^{7}$

Experimental design:

The pregnant rats were divided into two main groups; prenatal and postnatal. The prenatal group was 6 pregnant rats and the postnatal group was 6 pregnant rats.

(1) Prenatal group:

It was subdivided into 3 equal subgroups:

-Group I A gestational day 18 (GD18) Control subgroup: Pregnant rats were received oral doses of 1 $\mathrm{ml}$ of distilled water from the first day of pregnancy till GD18. ${ }^{8}$ Pregnant rats gave about 22 embryos.

-Group IB (GD18) treated subgroup: Pregnant rats were received a single daily dose of $10 \mathrm{mg}$ lead $/ \mathrm{Kg}$ body weight administrated orally by gastric tube from the first day of pregnancy till GD18 ${ }^{8}$ Pregnant rats gave about 20 embryos.

-Group I C (GD18) Lead plus Vitamin C subgroup: Pregnant rats were received a single oral daily dose of $10 \mathrm{mg}$ lead $/ \mathrm{Kg}$ body weight plus $40 \mathrm{mg}$ vit $\mathrm{C} / \mathrm{kg}$ body weight administrated orally by gastric tube from the first day of pregnancy till GD18. ${ }^{8}, 9$ Pregnant rats gave about 21 embryos.

(2) Postnatal group:

-Group II A post natal day 21 (PND21) Control subgroup: Pregnant rats were received oral doses of $1 \mathrm{ml}$ of distilled water from the first day of pregnancy till PND21. ${ }^{8}$ Pregnant rats gave about 22 embryos.

-Group II B (PND21) Lead-treated subgroup : Pregnant rats were received a single daily dose of $10 \mathrm{mg}$ lead/Kg body weight administrated orally by gastric tube from the first day of pregnancy till PND21. ${ }^{8}$ Pregnant rats gave about 20 embryos.

-Group III C (PND21) Lead plus Vitamin C subgroup: Pregnant rats were received a single oral daily dose of $10 \mathrm{mg}$ lead $/ \mathrm{Kg}$ body weight plus $40 \mathrm{mg}$ vit $\mathrm{C} / \mathrm{Kg}$ body weight administrated orally by gastric tube from the first day of pregnancy till PND21. ${ }^{8,9}$ Pregnant rats gave about 22 embryos.

At the end of experiment, in the prenatal groups, the pregnant mothers at the $18^{\text {th }}$ day of gestation were anaesthetized using ether inhalation, the abdomen and uterus was surgically opened and the fetuses were extracted then the abdomen of each fetus was opened and the kidney was extracted. In the postnatal groups, the offspring rats were anaesthetized using ether inhalation at expected date, the abdomen of each offspring was opened and the kidneys were extracted. The kidneys were processed for light microscopic (LM) and transmission electron microscopic (TEM) study. ${ }^{10,11}$ The kidney specimens for light microscopic study were stained by Haematoxylin and eosin stain (H\&E).

Collection of blood samples:

At the end of this experiment, blood samples were taken from offspring rats at (PND21) as it was difficult to collect blood samples from (GD18).Samples were taken from the rat tail in tubes, centrifuged for $15 \mathrm{~min}$ and then, processed for biochemical assays.

\section{Sample size estimation:}

By using Epi info program the minimum sample size required 110 pups so 12 female rats selected (each one gave about ten fetuses) and the pups subjected to assessment at GD18 and at PND21 depending on the following data:

Confidence level $=95 \%$

Power of the test $=85 \%$

Ratio of unexposed to exposed $=1$

Risk ratio $=1.74$

Odds ratio $=3.3$

Chemicals:

Lead was obtained from Sigma- Aldrich Company through Egyptian International Center Cairo- Egypt, in the form of white powder. One gm of lead was dissolved in $100 \mathrm{ml}$ distilled water, so each $1 \mathrm{ml}$ contained $10 \mathrm{mg}$ of lead. Vitamin C: It was obtained from Pfizer Egypt Pharmaceutical Company in the form of white powder soluble in water. One gm of vit $\mathrm{C}$ was dissolved in $100 \mathrm{ml}$ distilled water, so each 1 $\mathrm{ml}$ of solution contained $10 \mathrm{mg}$ vit C. ${ }^{8,9}$

Statistical analysis:

Data obtained from all groups were expressed as mean \pm standard deviation (SD) and subjected to statistical analysis using one-way analysis of variance (ANOVA) for comparison between the different groups. $\mathrm{P}$ values $<0.001$ were considered highly significant. 


\section{Light microscopic examination}

Group I A (GD18) Control subgroup: The outer renal cortex of fetal rat aged18days prenatal showed subcapsular zone containing the immature forms of renal developmental stages in the form of commashaped, S-shaped bodies, renal vesicle and immature glomeruli with indistinct Bowman's spaces and deep cortex showed more mature glomeruli with patent Bowman's spaces, proximal convoluted tubules (PCT) showed acidophilic granular cytoplasm and basal nuclei. The distal convoluted tubules (DCT) showed a dilated lumen (Figure $1 \mathrm{a}, \mathrm{b}$ ).

Group IB (GD18) treated subgroup: The kidney showed congested glomeruli with dilated Bowman's spaces (blue arrow), proximal tubules with partial loss of brush borders (red arrow) and mildly dilated distal tubules (green arrow) (Figure 1c).

Group I C (GD18) Lead plus Vitamin C subgroup: The kidney showed glomeruli with patent Bowman's spaces, proximal tubules with preserved brush borders and distal tubules with edematous epithelial lining (Figure 1d).

Group II A (PND21) Control subgroup: The renal cortex was formed of renal corpuscles and renal tubules with minimal interstitium containing peritubular capillaries. Each renal corpuscle consisted of a glomerulus containing a tuft of capillaries and surrounded by visceral and parietal

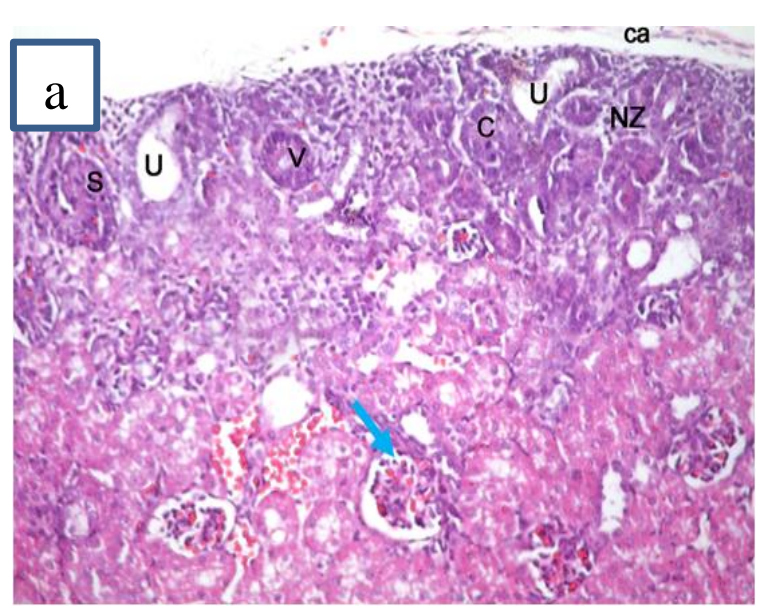

layers of Bowman's capsule which were separated by Bowman's space. The outer parietal layer was formed of flat cells while the inner visceral layer was closely related to the glomerular capillaries. The cortical renal tubules were formed of proximal and distal convoluted tubules. They were lined by simple cuboidal epithelium with central rounded nuclei (Figure 2a).

Group II B (PND21) Lead treated subgroup: The renal corpuscles appeared with average Bowman's space while others contained shrunken glomeruli and narrow Bowman's space. Proximal tubules appeared with partial loss of brush border, the distal tubules appeared with intraluminal debris and small areas of interstitial hemorrhage (Figure 2b).

Group III C (PND21) Lead plus Vitamin C subgroup: The renal cortex showed normal histological architecture. All renal corpuscles were normal, having intact Bowman's capsule surrounded by normal Bowman's space. The proximal tubules were lined with cuboidal or low columnar cells and their lumina were narrowed by the presence of long microvilli of the brush border. The distal convoluted tubules were normal and lined with low cuboidal cells having spherical nuclei but less acidophilic cytoplasm. The tubular basement membrane was intact. The blood vessels appeared congested (Figure 2c).

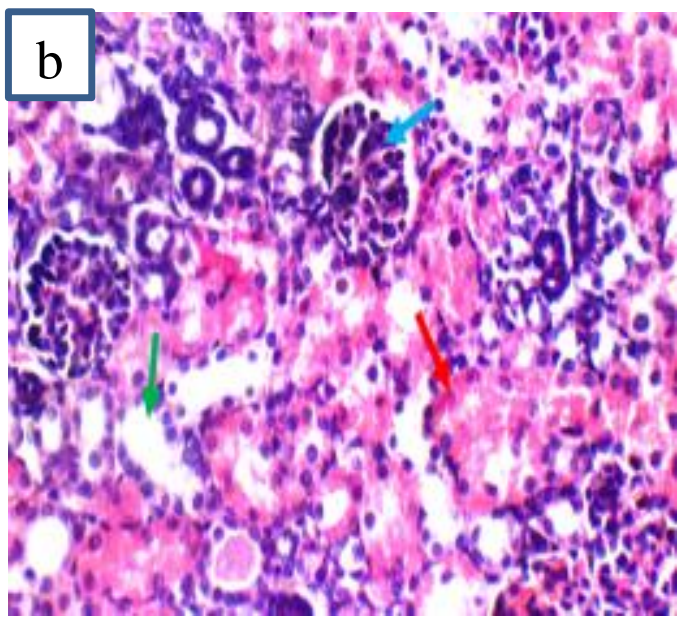



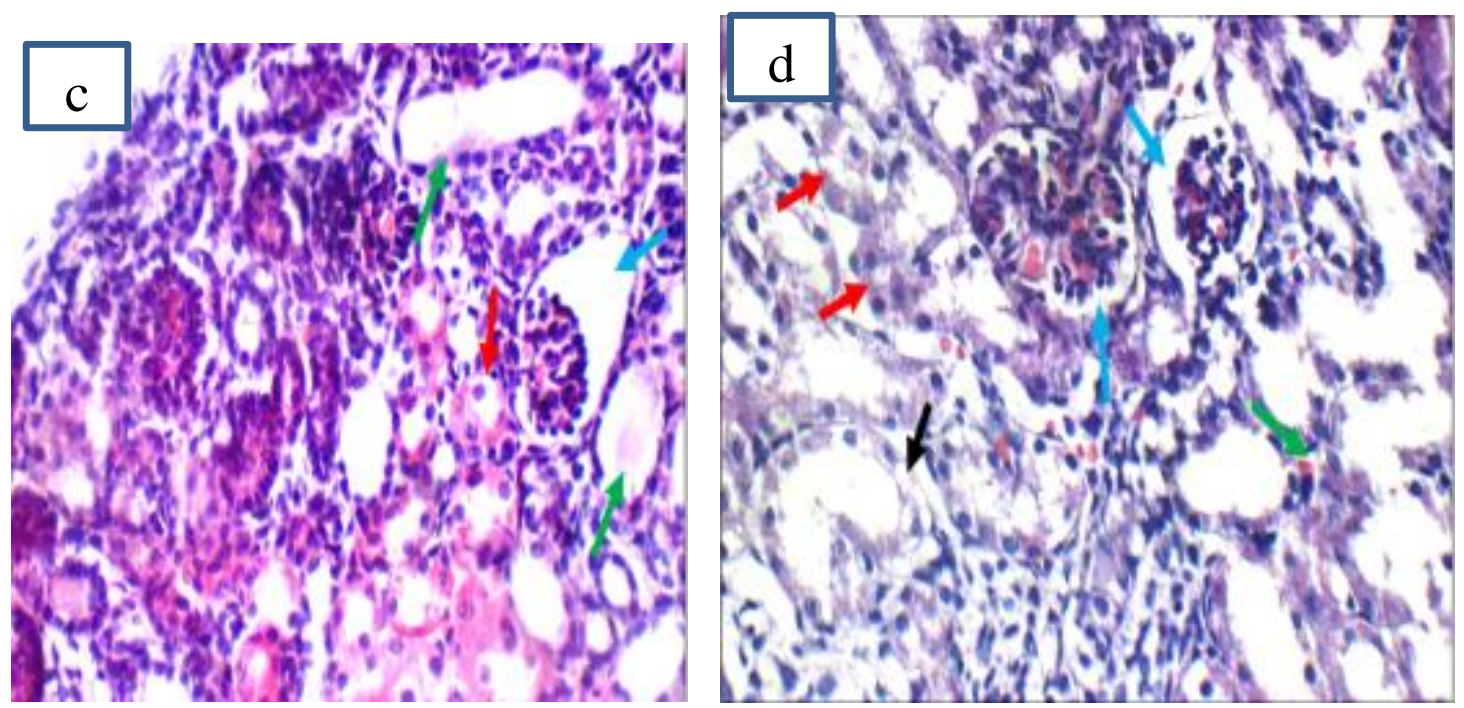

Fig.1: Light photomicrographs of kidney section of rat fetus aged 18 days: a) Control group showing the renal vesicle (V), comma-shaped body (C) and S-shaped body (S) arranged close to the capsule (ca) and mature glomeruli in deep cortex (blue arrow). Ureteric buds (U) were seen in the nephrogenic zone (NZ) (H\&E X 200). b) Control group showing glomeruli (blue arrow) with patent Bowman's spaces, proximal tubules showed acidophilic granular cytoplasm and basal nuclei (red arrow) and distal tubule showed wide lumen (green arrow). c) Leadtreated group showing congested glomeruli with dilated Bowman's spaces (blue arrow), proximal tubules with partial loss of brush borders (red arrow) and mildly dilated distal tubules (green arrow). d) Lead treated plus vitamin C group showing glomeruli with patent Bowman's spaces (blue arrow), proximal tubules with preserved brush borders (red arrow), scattered distal tubules with mildly edematous epithelial lining (black arrow) and average interstitium (green arrow) (H\&E X 400).
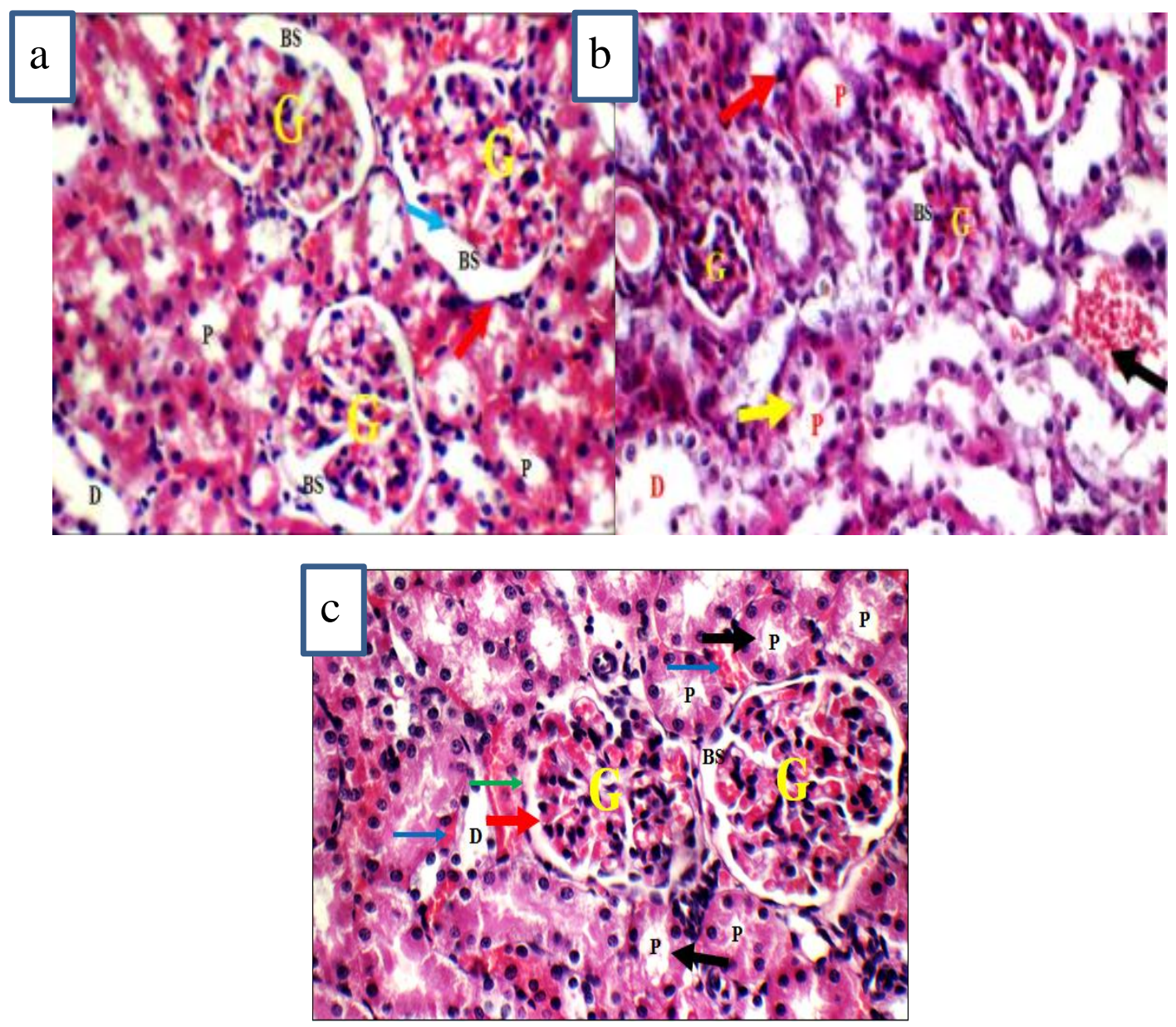
Fig.2: Light photomicrographs of kidney section of newborn rat at PND21: (a) Control group showing glomeruli (G) and Bowman's capsule with its visceral (blue arrow) and parietal (red arrow) layers and distinct Bowman's space (BS). The proximal convoluted tubules (P) consist of columnar cells with rounded basal and vesicular nuclei. The distal convoluted tubules (D) have low cubical cells with vesicular nuclei and wide lumen. b) Lead treated group showing small-sized distorted glomeruli $(\mathrm{G})$ with average Bowman's spaces (BS), proximal tubules (P) with partial loss of brush border (yellow arrow), apoptotic epithelial lining (red arrow), the distal tubules (D) appear with intraluminal debris and small areas of interstitial hemorrhage (black arrow). c) Lead plus vitamin C group showing average glomeruli (G) with visceral (red arrow) and parietal (green arrow) of Bowman's capsule separated by Bowman's space (BS), average proximal tubules (P) with preserved brush border (black arrow), average distal tubules (D), and mildly congested interstitial blood vessels (blue arrow) (H\&E X 400).

\section{Electron microscopic examination}

Group I A, I C (GD18) Control subgroup: The cells lining the proximal convoluted tubule had a single round nuclei. Its cytoplasm containing many mitochondria. These cells had few short apical microvilli. The cells lining the distal convoluted tubules showed few microvilli and wide lumen. These cells showed spherical basal nuclei. The cytoplasm of these cells containing few mitochondria. The glomerular filter consisted of three components from inward to outwards: fenestrated capillary endothelium, glomerular thin basal lamina and foot processes of podocyte (Figure $3 \mathrm{a}, \mathrm{b}, \mathrm{c}, \mathrm{d})$.

Group IB (GD18) treated subgroup: The proximal tubular cells contained rounded basally located euchromatic nuclei with prominent nucleoli. The cytoplasm showed markedly swollen mitochondria, numerous cytoplasmic vacuoles, numerous cytoplasmic inclusions, and partial loss of brush borders. The cells lining the distal convoluted tubules had small sized, shrinked nucleus with few short microvilli. The cytoplasm showed multiple vacuoles and multiple epithelial intra luminal debris. In comparison with control group, the glomerular filter showed adhesion between the foot processes of podocytes. The basal lamina showed large area of thickening (Figure 4a, b, c).
Group II A, II C (PND21) Control subgroup: The proximal tubules were lined with columnar cells which had large rounded euchromatic nuclei, apical microvilli. The cytoplasm containing elongated mitochondria. The cells lining the distal tubule had large oval nucleus with central nucleoli and condensed chromatin in the periphery. Its lumen showed few microvilli. Numerous, elongated and round-shaped mitochondria were seen within their cytoplasm. The glomerular filter consisted of fenestrated endothelium, basal lamina with regular thickness and the primary and secondary foot processes had slit pores between them (Figure 5a, b, c, d).

Group II B (PND21) Lead treated subgroup: The proximal convoluted tubular cells contained oval, rounded, irregular and heterochromatic pyknotic nuclei. Numerous swollen and vacuolated mitochondria, scattered cytoplasmic vacuoles and partial loss of brush borders. The distal tubular cells showed wide tubular lumen, multiple intra luminal debris and complete loss of the apical microvilli. Some nuclei become shrunken with loss of peripheral heterochromatin. The glomerular capillaries appeared with loss of their architecture and irregular basement memberane.The podocyte appeared with distorted foot processes (Figure 6a, b, c).

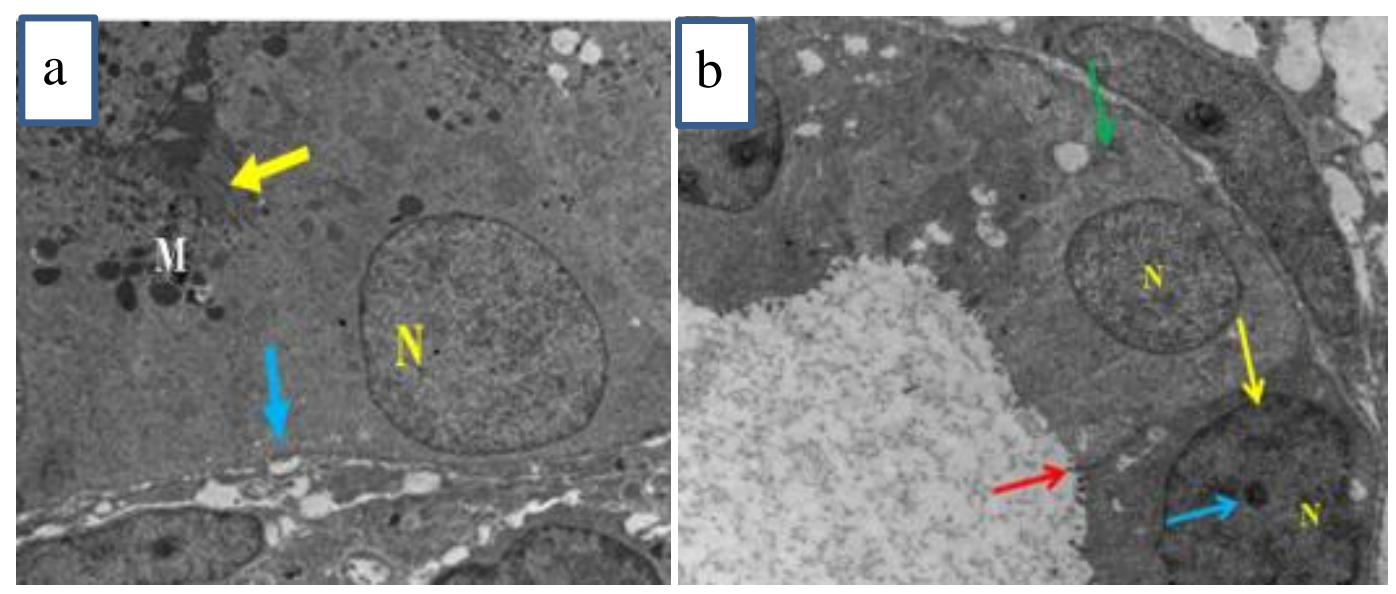




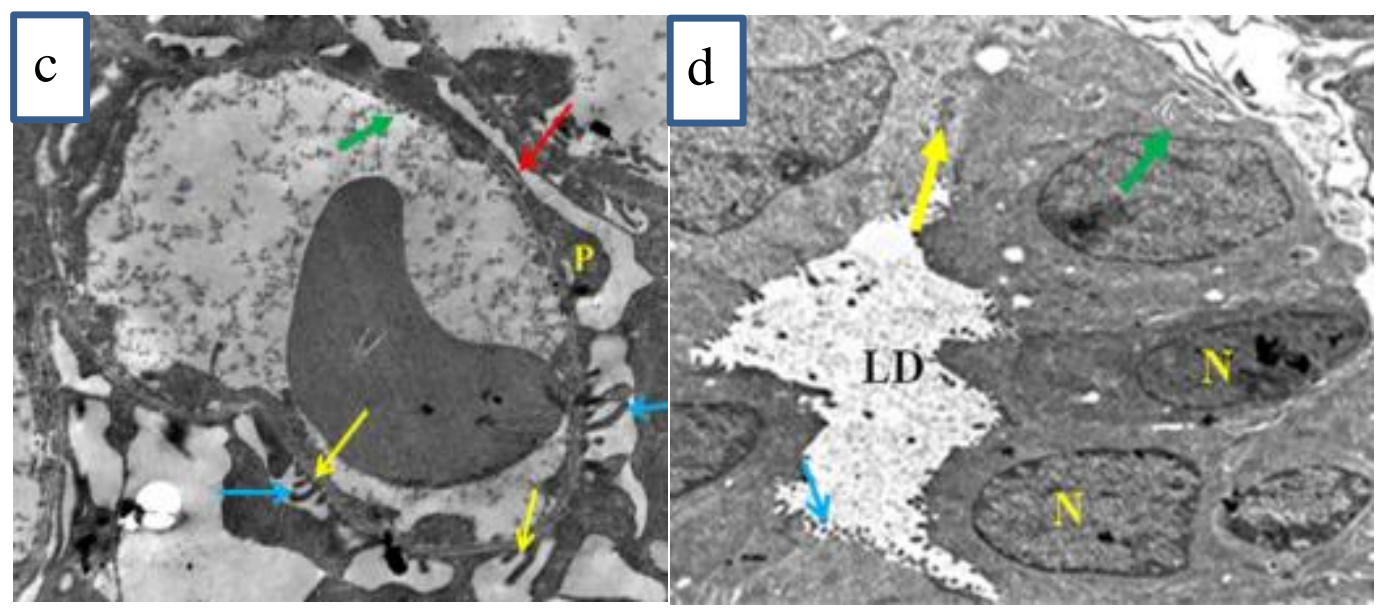

Fig.3: Electron photomicrographs of ultrathin section in kidney of rat fetus aged 18 days: a) Control group showing a part of proximal convoluted tubule lined with columnar cells which have a large round nucleus $(\mathrm{N})$ and intact basement membrane (blue arrow). The cytoplasm showing many mitochondria (M) and few short apical microvilli (yellow arrow) (TEM. X8000). b) Control group showing distal tubule showing cells with few short microvilli (red arrow), round centrally located nuclei $(\mathrm{N})$ with central nucleoli (blue arrow) and condensed chromatin in the periphery (yellow arrow) and average mitochondria (green arrow) (TEM. X8000). c) Control group showing part of glomerulus with the components of its filter consisting of fenestrated capillary endothelium (green arrow), glomerular thin basement membrane (red arrow), podocyte $(\mathrm{P})$ with long thin foot processes (blue arrow), and patent filtration slits (yellow arrow) (TEM. X12000). d) Lead plus vitamin C group showing distal convoluted tubule with dilated lumen, short microvilli (blue arrow) and multiple epithelial intra luminal debris (LD). The nucleus (N) appeared spherical with normal chromatin distribution. Mitochondria (yellow arrow) are seen distributed in the cytoplasm and within regular basal infoldings (green arrow) perpendicular to the basement membrane (TEM. X8000).

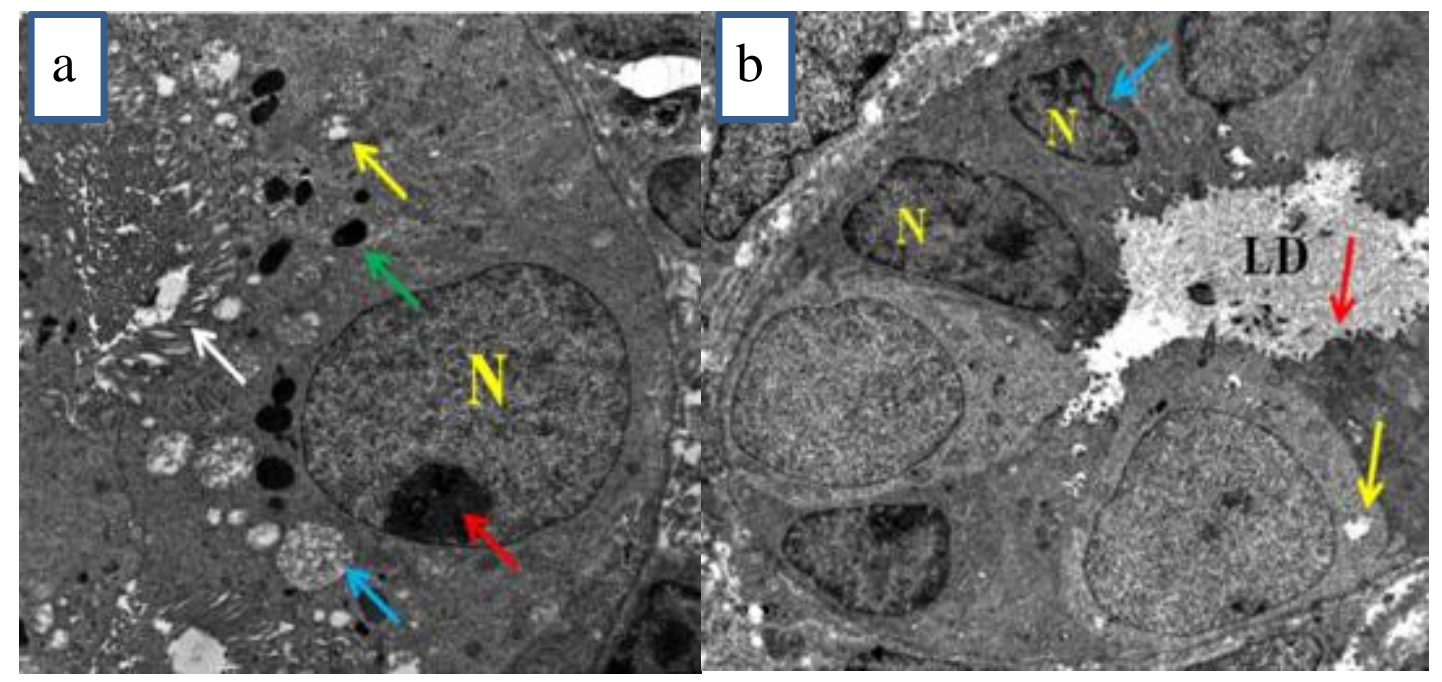




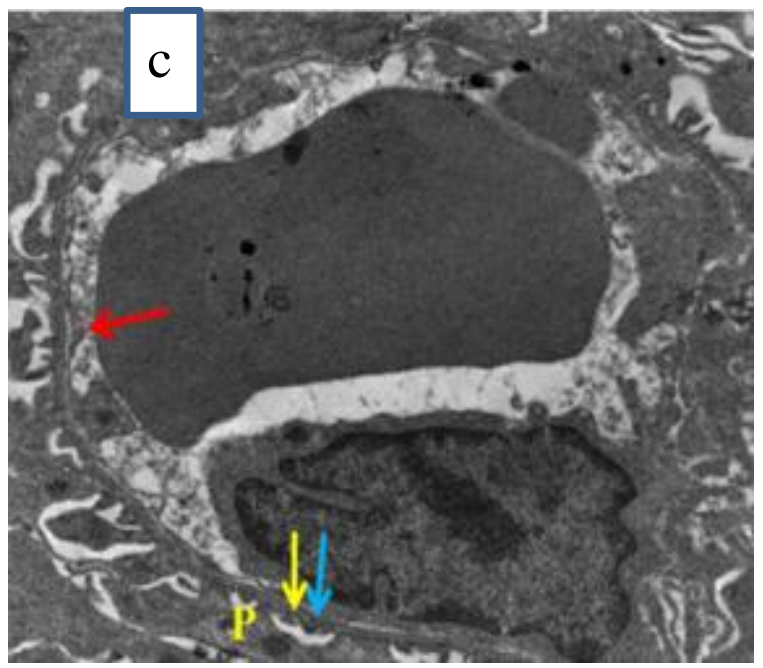

Fig.4: Eelectron photomicrographs of ultrathin section in kidney of rat fetus aged 18 days: (a) Lead treated group showing proximal tubule with basally located nuclei $(\mathrm{N})$ and prominent nucleolus (red arrow), markedly swollen mitochondria (blue arrow), numerous cytoplasmic vacuoles (yellow arrow), numerous cytoplasmic inclusions (green arrow), and partial loss of brush borders (white arrow) (TEM. X8000). b) Lead treated group showing distal tubule with few short microvilli (red arrow), pyknotic nuclei $(\mathrm{N})$ with clumped chromatin in the periphery (blue arrow), scattered cytoplasmic vacuoles (yellow arrow) and multiple epithelial intra luminal debris (LD) (TEM.X6000).c) Lead treated group showing part of glomerulus with thick basement membrane (red arrow), podocytes (P) with fused foot processes (blue arrow), and narrow filtration slits (yellow arrow) (TEM. X12000).
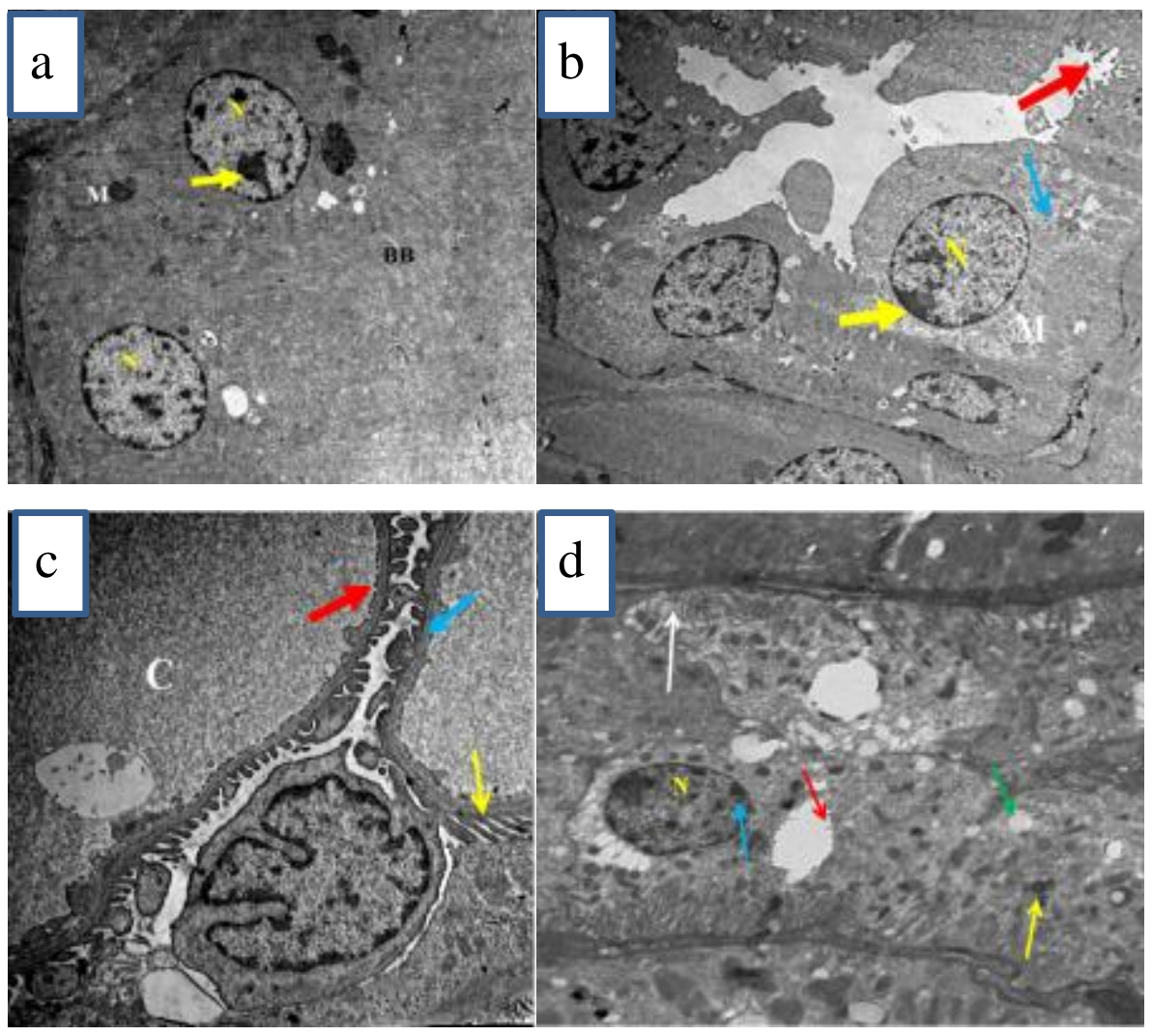

Fig.5: Electron photomicrographs of ultrathin section in kidney of newborn rat at PND21: (a) Control group showing a part of the proximal convoluted tubule contains large euchromatic oval nucleus $(\mathrm{N})$ with prominent nucleoli (yellow arrow). The cytoplasm contains mitochondria (M) and preserved brush border (BB) (TEM.X8000).b) Control group showing a part of distal convoluted tubule with oval nucleus $(\mathrm{N})$ and condensed chromatin in the periphery (yellow arrow), few short microvilli (red arrow), average cytoplasm (blue arrow) and elongated mitochondria (M) (TEM. X5000). c) Control group showing glomerular capillary (C) with regular basement membrane (blue arrow), fenestrated endothelium (red arrow) and average foot processes of podocyte (yellow arrow) (TEM. X15000).d) Lead plus vitamin C group showing distal tubule with few short microvilli (red arrow), average nuclei $(\mathrm{N})$ with prominent nucleoli (blue arrow), average mitochondria (yellow arrow), few cytoplasmic vacuoles (green arrow), and basal infoldings (white arrow) (TEM. X 6000). 

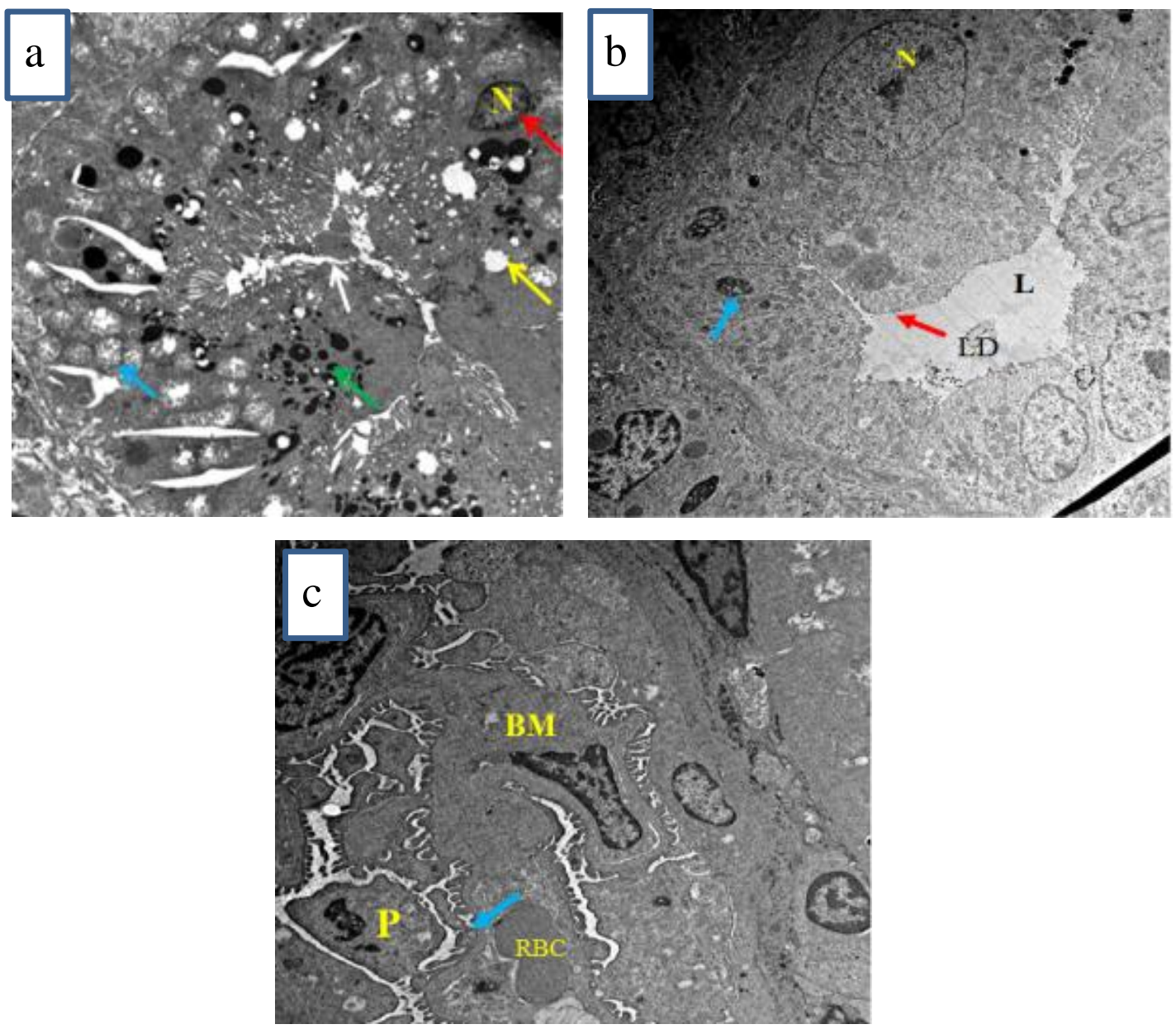

Fig.6: Electron photomicrographs of ultrathin section in kidney of newborn rat at PND21: (a) Lead treated group showing proximal tubule with basally located pyknotic nuclei $(\mathrm{N})$ and clumped chromatin (red arrow), markedly swollen and vacuolated mitochondria (blue arrow), numerous cytoplasmic vacuoles (yellow arrow), numerous cytoplasmic inclusions (green arrow), and partial loss of brush borders (white arrow) (TEM. X5000). b) Lead treated group showing a part of distal convoluted tubule with wide tubular lumen $(\mathrm{L})$, multiple intra luminal debris (LD) and complete loss of the apical microvilli(red arrow). The nucleus was swollen and irregular with loss of peripheral heterochromatin $(\mathrm{N})$ and some nuclei are shrunken and apoptotic (blue arrow) (TEM.X4000).c) Lead treated group showing part of glomerulus with the processes of podocyte (blue arrow) appeared distorted with loss of their uniform appearance. The basement membrane (BM) showed large area of thickening and RBC becomes congested (TEM.6000X).

Body weight study

Estimation of the body weight (gm) of offspring rats between the studied groups:

There was a significant statistical difference between weight of rat fetuses (at GD18) in control group and weight of rat fetuses treated with lead and treated with lead plus vit.C. There was a significant statistical difference between weight of rat pups (at PND21) in control group and weight of rat pups treated with lead and treated with lead plus vit.C (Tables 1,2).

\begin{tabular}{|c|c|c|c|c|c|c||}
\hline Weight $(\mathrm{gm})$ & Control $(\mathrm{n}=8)$ & $\begin{array}{c}\text { Treated with } \\
\text { Lead } \\
(\mathrm{n}=8)\end{array}$ & $\begin{array}{c}\text { Lead + Vitamin } \\
\mathrm{C} \\
(\mathrm{n}=8)\end{array}$ & $\begin{array}{c}\text { ANOVA F } \\
\text { test }\end{array}$ & $p$ value & Post Hoc Test \\
\hline Mean \pm SD & $2.01 \pm 0.03$ & $1.04 \pm 0.03$ & $1.5 \pm 0.12$ & 296.1 & 0.001 & $\begin{array}{r}\mathrm{P} 1=0.001 \\
\mathrm{P} 2=0.001 \\
\mathrm{P} 3=0.001\end{array}$ \\
\hline
\end{tabular}

Table 1: Weight distribution of offspring rats at (GD18) among studied groups.

P1: (Control \& Lead) P2: (Control \& Lead plus vit.C) P3: (Lead \&Lead plus vit.C) n: number of rat fetuses. 


\begin{tabular}{|c|c|c|c|c|c|c|}
\hline Weight (gm) & $\begin{array}{c}\text { Control } \\
(\mathrm{n}=8)\end{array}$ & $\begin{array}{c}\text { Treated with } \\
\text { Lead } \\
(\mathrm{n}=8)\end{array}$ & $\begin{array}{c}\text { Lead }+ \\
\text { Vitamin } \\
(\mathrm{n}=8)\end{array}$ & $\begin{array}{c}\text { ANOVA F } \\
\text { test }\end{array}$ & $p$ value & Post Hoc Test \\
\hline Mean \pm SD & $28.2 \pm 0.11$ & $22.3 \pm 0.04$ & $26.4 \pm 0.19$ & 3932.2 & 0.001 & $\begin{array}{r}\mathrm{P} 1=0.001 \\
\mathrm{P} 2=0.001 \\
\mathrm{P} 3=0.001\end{array}$ \\
\hline
\end{tabular}

Table 2: Weight distribution of offspring rats at (PND21) among studied group.

P1: (Control \& Lead) P2: (Control \& Lead plus vit.C) P3: (Lead \&Lead plus vit.C) n: number of rat pups.

Biochemical results

Estimation of the mean values of level of serum urea and creatinine (mg/dl) at (PND21)

There was a significant statistical difference between serum urea levels of rat pups (at PND21) in control group and weight of rat pups treated with lead and treated with lead plus vit.C. There was a significant statistical difference between serum creatinine level of rat pups (at PND21) in control group and serum creatinine level of rat pups treated with lead and treated with lead plus vit.C (Tables 3, 4).

\begin{tabular}{|c|c|c|c|c|c|c|}
\hline Urea (mg/dl) & $\begin{array}{c}\text { Control } \\
(\mathrm{n}=8)\end{array}$ & $\begin{array}{c}\text { Treated with } \\
\text { Lead } \\
(\mathrm{n}=8)\end{array}$ & $\begin{array}{c}\text { Lead + Vitamin } \\
\mathrm{C} \\
(\mathrm{n}=8)\end{array}$ & $\begin{array}{c}\text { ANOVA F } \\
\text { test }\end{array}$ & $p$ value & Post Hoc Test \\
\hline Mean \pm SD & $20.6 \pm 0.4$ & $47.8 \pm 0.5$ & $23.4 \pm 0.38$ & 8597.3 & 0.001 & $\begin{array}{r}\mathrm{P} 1=0.001 \\
\mathrm{P} 2=0.001 \\
\mathrm{P} 3=0.001\end{array}$ \\
\hline
\end{tabular}

Table 3: Serum urea distribution of offspring rats at (PND21) among studied groups.

P1: (Control \& Lead) P2: (Control \& Lead plus vit.C) P3: (Lead \&Lead plus vit.C) n: number of rat pups.

\begin{tabular}{|c|c|c|c|c|c|c|}
\hline Creatinine (mg/dl) & $\begin{array}{c}\text { Control } \\
(n=8)\end{array}$ & $\begin{array}{c}\text { Treated with } \\
\text { Lead } \\
(n=8)\end{array}$ & $\begin{array}{c}\text { Lead + Vitamin } \\
\text { C } \\
(n=8) \\
\end{array}$ & $\begin{array}{c}\text { ANOVA F } \\
\text { test }\end{array}$ & $\overline{p \text { value }}$ & Post Hoc Test \\
\hline Mean \pm SD & $0.6 \pm 0.06$ & $2.3 \pm 0.4$ & $1.3 \pm 0.3$ & 54.1 & 0.001 & $\begin{array}{l}\mathrm{P} 1=0.001 \\
\mathrm{P} 2=0.002 \\
\mathrm{P} 3=0.001\end{array}$ \\
\hline
\end{tabular}

Table 4: Serum creatinine distribution of offspring rats at (PND21) among studied groups.

P1: (Control \& Lead) P2: (Control \&Lead plus vit.C) P3: (Lead \& Lead plus vit.C) n: number of rat pups.

\section{DISCUSSION}

Lead toxicity has been recognized as a major environmental health hazard worldwide affecting both humans and animals at all ages especially young children in humans ${ }^{12}$. In the present work, the outer renal cortex of group IA revealed the subcapsular zone containing immature forms of renal developmental stages in the form of S-shaped bodies, comma-shaped, renal vesicles and immature glomeruli which appeared as a dense rounded structure, whereas the deeper parts of the cortex had mature renal glomeruli. The proximal tubules were lined by simple cuboidal epithelium with basal nuclei. The distal tubules showed a wide lumen. The same finding was observed by others..$^{13,14,15}$
In group IIA the renal cortex showed mature glomeruli that have visceral layer, parietal layer and renal space in between. The PCT consisted of columnar cells with vesicular basal nuclei and narrow lumen. The DCT had low cubical cells with wide lumen. These results were in agreement with Mohamed and Saleh ${ }^{16}$ and Brown et al. ${ }^{17}$ who founded that the renal cortex is formed of renal corpuscle consisted of a glomerular capillary tuft surrounded by Bowman's capsule.

In the present study, both (IB, IIB groups) showed affection of glomeruli, some of them showed dilatation of Bowman' $s$ capsule and shrunked glomerular tufts, but some glomeruli appeared normal. The PCTs were degenerated and had vacuolated cytoplasm with pyknotic nuclei. Some 
DCTs were degenerated. This was in agreement with Mohamed and Saleh. ${ }^{16}$

In the current study, group IC and group IIC revealed the normal histological structure as group IA, IIA. These results were in agreement with Jabeen et al. ${ }^{18}$

In the current work, electron microscopic examination of (IA, IIA groups) showed that the proximal convoluted tubules were lined with columnar cells which had large rounded euchromatic nuclei and apical microvilli. The lining epithelial cells of the distal convoluted tubules appeared with euchromatic nuclei. Its lumen showed few microvilli. The glomerular blood capillaries lined with fenestrated endothelium. The glomerular basement membrane appeared regular. Podocytes with their euchromatic nuclei were also noticed. They had primary and secondary foot processes. These results were observed by previous studies. ${ }^{13,14}$

By electron microscopic examination, in (IB, IIB groups) the cells lining the proximal tubule showed vacuolated mitochondria, their microvilli were few and the lumen was wide, the cells lining the distal tubules had small sized, shrinked nucleus, the cytoplasm showed multiple vacuoles. The mitochondria were degenerated. The luminal surface of these cells was irregular. The glomerular filter showed adhesions between the foot processes of podocytes. The basal lamina showed large areas of thickening. These results were observed by previous studies. ${ }^{1,19}$

In the present study, in group IC and group IIC some cells lining the proximal tubules showed rounded euchromatic nucleus, closely-packed microvilli. Its cytoplasm showed scattered vacuoles and mitochondria with average cristae, dense long microvilli and well defined brush border. The glomerular filter had small area of thickening in the basal lamina. The cells lining distal convoluted tubule revealed regular basement membrane, few microvilli and cytoplasmic vacuoles. This was in agreement with Jabeen et al. ${ }^{18}$ who reported that the kidney in vitamin $\mathrm{C}$ and lead administrated rats showed restoration in normal nephron structure with mild congestion of renal blood vessel and mild intraluminal hyaline casts.

In the current work, the levels of serum creatinine and urea were increased in group IIB. This data was in accordance with previous studies. ${ }^{20,21}$

Our findings revealed in group IIC that when vitamin $\mathrm{C}$ was given concomitantly with lead there were decrease of serum urea and creatinine toward the level of the control group. Therefore, vitamin C can partially normalize the biochemical parameters when it co-administrated with lead. This was in agreement with Jabeen et al ${ }^{18}$

In the present study, there were significant decrease in body weight of offspring rats of both (IB, IIB group).These data were in agreement with Jabeen et al. ${ }^{18}$ who noticed early neonatal exposure to lead caused a decrease in body weight in rats and mice. However, there were improvement in body weight in (IB, IIB group) when vitamin C and lead were given together. These results were in agreement with Ayind et al. ${ }^{9}$.

\section{CONCLUSION}

Lead affects the kidney of the developing rat during prenatal and postnatal periods. Lead produces oxidative damage in the kidney Therefore, exposure to lead, either occupationally or through the diet, must be restricted, especially during pregnancy and lactation. Vitamin C, a known chelating agent with non-enzymatic antioxidant features, has been suggested to protect cells from oxidative stress in lead-exposed rats.

\section{REFERENCES}

1. Deveci E, Soker S, Baran O, et al. Ultrastructural changes in the kidney cortex of rats treated with lead acetate.Int. J. Morohol., 2011; 29(3): 1058-61.

2. Ramya S and Prasanna G. Nephroprotective Effect of Camellia sinensis L. On Lead Acetate Induced Male Albino Rats. International Journal of Pharm. Tech. Research, 2013; 5 (2): 511-15

3. Dart RC, Hurlbut KM, Boyer-Hassen LV, et al. Lead. In: Medical Toxicology (Dart TC, ed), 3rd ed Philadelphia: Lippincott Williams \& Wilkins, 2004; Pp. 1423-31.
4. Kojo S. Vitamin C: basic metabolism and its function as an index of oxidative stress. Curr Med Chem., 2004; 11:1041-64.

5. Ray S, Roy K, Sengupta C, et al. Exploring the protective effect of ascorbic acid and a queous extract of spirulina platensis on methotrexateinduced lipid peroxidation. Iranian Journal of Pharmaceutical Science, 2007; 3(4):217-28.

6. Naidu KA. Vitamin $\mathrm{C}$ in human health and disease is still A mystery An overview. Nutr J., 2003; 2: 7-16.

7. Adu EK and Yeboah S. The efficacy of the vaginal plug formation after mating for 
pregnancy diagnosis and embryonic resorption in utero in the Greater Cane rat (Thryonomys swinderianus, temminck). Troop Anim Health Prod., 2000; 32 (1):1-10.

8. Jabeen R, Tahir M, Waqas S, et al. Teratogenic effects of lead acetate on kidney. J Ayub Med Coll Abbottabad, 2010; 22(1): 76-79.

9. Ayinde OC, Ogunnowo S, Ogedegbe RA, et al. Influence of vitamin $\mathrm{C}$ and vitamin $\mathrm{E}$ on testicular zinc content and testicular toxicity in lead exposed albino rats. BMC Pharmacol Toxicol., 2012; 13:1-8.

10. Hegazy R and Hegazy A. Hegazy' simplified method of tissue processing (consuming time and chemicals). Ann. Int. Med.Dent. Res.2015;1(2): 57-61.

11. Tizro P, Choi C, Khanlou N. Sample Preparation for Transmission Electron Microscopy. Methods Mol Biol. 2019; 1897: 417-24.

12. Lalith Kumar $\mathrm{V}$ and Muralidhara $\mathrm{M}$. Ameliorative effects of ferulic acid against lead acetate-induced oxidative stress, mitochondrial dysfunctions and toxicity in prepubertal rat brain. Neurochem Res., 2014; 39: 2501-15.

13. Abdel-Aziz HA and Mohamed HK. A histological study on the effect of prenatal and postnatal administration of monosodium glutamate on the developing renal cortex of male albino rats. Egypt J Histol., 2013; 36:47082.

14. El-gammal AA, Ibrahim OY, Shaban SF, et al. Postnatal development of the albino rat renal cortex (histolgical study). Egypt J Histol., 2010; $33: 745-56$

15. Marquez MG, Cabrera I, Serrano DJ, et al. Cell proliferation and morphometric changes in the rat kidney during postnatal development. Anat Embryol., 2002; 205: 431- 40.

16. Mohamed NA and Saleh SM. Effect of pre-and postnatal exposure to lead acetate on the kidney of male albino rat: A light and electron microscopic study. Egypt J Histol., 2010; 33(2): 365-79.

17. Brown DL, Walling BE, Mattix ME, et al. Urinary system. In: Atlas of histology of the juvenile rat. San Diego, CA: Elsevier. 2016; 395-422.

18. Jabeen R, Tahir M, Muhammad S, et al. Protective Role of Vitamin $\mathrm{C}$ against Teratogenic Effects of Lead Acetate on Mouse Kidney. PJMHS, 2011; 5(3) :425-29.

19. Hotta $\mathrm{O}$, Inoue $\mathrm{CN}$, Miyabayashi $\mathrm{S}$, et al. Clinical and pathologic features of focal segmental glomerulosclerosis with mitochondrial tRNALeu. (UUR) gene mutation. Kidney Int., 2001; 59(4):1236-43.
20. Aprioku S and Siminialay M. Maternal lead exposure and pregnanacy outcome in Wistar albino rats. Journal of Toxicology and Environmental Health Sciences, 2013; 5(10):185-93.

21. Vyskocil A, Cizkova M, Tejnorva I, et al. Effect of prenatal and postnatal exposure to lead on kidney function in male and female rats. Journal of Applied Toxicology, 1995; 15(4):327-28. 